\title{
Estudantes concluintes do ensino médio público de Porto Alegre: entre a expansão do acesso à escolarização e a seletividade escolar
}

\author{
Célia Elizabete Caregnato ${ }^{1}$ \\ Leandro Raizer ${ }^{2}$ \\ Murilo Marreco Pedroso ${ }^{3}$ \\ Marcela de Andrade Rufato ${ }^{4}$
}

\begin{abstract}
Resumo:
O objetivo do presente artigo é analisar elementos do perfil de estudantes que frequentam o terceiro ano do ensino médio de escolas públicas da cidade de Porto Alegre. Para tanto, revisou-se aspectos da ampliação do acesso à educação formal e da política curricular para esse nível de ensino no Rio Grande do Sul. Os dados foram obtidos por meio de survey, aplicado em 2018, entre estudantes de escolas públicas das redes municipal, estadual e federal. Detalhou-se as respostas às questões do survey relativas a características familiares e de hábitos de estudos. Identificou-se que, majoritariamente, seus pais possuem formação secundária e com renda familiar pouco acima da média nacional; têm hábito de leitura abaixo da média nacional e dedicam poucas horas a estudos para além do tempo na escola. Esses resultados evidenciaram um viés reprodutivo do capital escolar acumulado pelas familias e uma relativa homogeneidade entre os estudantes, indicando que há um processo de seletividade no próprio percurso do ensino médio.
\end{abstract}

\section{Palavras-chave:}

Estudantes. Ensino médio. Seletividade escolar.

\section{Public upper secondary education seniors in Porto Alegre: between the expansion of access to education and school selectivity}

\footnotetext{
Abstract: The purpose of this article is to analyze aspects of the profile of students who attend the last year of high school in public schools in the city of Porto Alegre. To this end, characteristics of the process of expansion of access to formal education and Rio Grande do Sul state curriculum policies for upper secondary education were reviewed. Data were obtained through a survey applied in 2018

1 Doutora em Educação, Professora da Universidade Federal do Rio Grande do Sul. E-mail: celia.caregnato@gmail.com. ORCID iD: http://orcid.org/0000-0002-9326-590X.

2 Doutor em Sociologia, Professor da Universidade Federal do Rio Grande do Sul. E-mail: leandro.raizer@gmail.com. ORCID iD: http://orcid.org/0000-0002-0406-7670.

3 Mestre em Educação. E-mail: murilompedroso@gmail.com. ORCID iD: http://orcid.org//0000-0003-3095-6727.

4 Mestre em Sociologia, Professora da Universidade Federal de Alfenas (MG). E-mail: marufato@yahoo.com.br. ORCID iD: http://orcid.org/0000-0002-8646-4919.
} 
among students from public schools maintained by municipal, state and federal governments. The answers to the survey questions related to family characteristics and study habits were detailed. It was identified that most students have parents with secondary education; their family in come is slightly above the national average; their reading habits are below the national average; and they devote few hours to studies beyond their time at school. These results showed a reproductive bias in the school capital accumulated by families and a relative homogeneity among students, indicating that there is likely a process of selectivity in the very course of upper secondary education.

Keywords: Students. Upper secondary education. School selectivity.

\section{Estudiantes concluyentes de secundaria en escuelas públicas de Porto Alegre: entre la expansión del acceso a la escolarización y la selectividad escolar}

Resumen: El propósito de este artículo es analizar aspectos del perfil de los estudiantes que cursan el último año de secundaria en las escuelas públicas de la ciudad de Porto Alegre. Para ello, se revisaron características del proceso de ampliación del acceso a la educación formal y la política curricular para este nivel educativo en el estado de Rio Grande do Sul. Los datos fueron obtenidos a través de una encuesta aplicada en 2018 entre estudiantes de escuelas públicas de las redes municipal, estatal y federal. Se detallaron las respuestas a las preguntas de la encuesta relacionadas con características familiares y hábitos de estudio. Se identificó que, en su mayoría, los alumnos tienen padres con educación secundaria; ingresos familiares levemente por encima del promedio nacional; hábitos de lectura por debajo del promedio nacional; y dedican pocas horas a estudios más allá de su tiempo en la escuela. Estos resultados mostraron un sesgo reproductivo del capital escolar acumulado por las familias y una relativa homogeneidad entre los estudiantes, indicando un posible proceso de selectividad en el curso de la secundaria.

Palabras clave: Estudiantes. Educación Secundaria. Selectividad Escolar.

\section{Introdução}

Desde a redemocratização, nota-se no Brasil uma efetiva ampliação do acesso à educação formal, que foi estabelecida como direito subjetivo pela Constituição Federal de 1988. A escolarização obrigatória foi ampliada até os 17 anos, correspondendo idealmente à conclusão do ensino médio, porém apenas o acesso ao ensino fundamental pode ser considerado universalizado até o momento.

Este artigo discute aspectos do ensino médio no Rio Grande do Sul, particularmente o perfil de estudantes ${ }^{1}$ concluintes de escolas públicas das redes municipal, estadual e federal da cidade de Porto Alegre. O objetivo foi, a partir da perspectiva das estratificações educacionais, analisar algumas características com relação à composição familiar e os hábitos de estudos dos estudantes que têm conseguido chegar ao terceiro ano do ensino médio.

A literatura que problematiza a escolarização de nível médio adota diversas abordagens temáticas e teóricas para analisar essa etapa tratando, por exemplo, de desenhos curriculares

\footnotetext{
1 Os dados discutidos neste artigo foram produzidos no âmbito do projeto intitulado Desigualdade, diversidade e reconhecimento na Educação: novos públicos da escolarização média e superior, aprovado pelo Comitê de Ética em Pesquisa sob o parecer 1.886.072. O bolsista de iniciação científica pelo Conselho Nacional de Desenvolvimento Científico e Tecnológico (CNPq), Weslley D. B. Moraes, apoiou o trabalho que tornou o artigo possível entre 2019/2020.
} 
(ZIBAS, 2005; MOEHLECKE, 2012; FERRETI; SILVA, 2017); de relações entre juventude e formação técnico-profissional (FRIGOTTO, 2007); de políticas públicas e interesses econômicos relacionados (KRAWCZYK, 2011; KRAWCZYK; SILVA, 2017); da noção de formação integral (MOLL, 2014); e, ainda, do ensino médio integrado (SALES; VASCONCELOS, 2016). Esse conjunto de estudos contribuiu para que trabalhássemos com a perspectiva de que a escolarização de nível médio é relativamente mais seletiva que a do fundamental. A norma legal de obrigatoriedade da educação básica se depara com desigualdades quanto às possibilidades de acesso e permanência. Muitas vezes, responsabilidades assumidas pelos jovens devido a condições socioeconômicas e geográficas limitam as possibilidades de frequência à escola.

As trajetórias dos estudantes podem ser entendidas parcialmente por meio do capital socioeconômico que possuem. A escola é um importante espaço de sociabilidade juvenil e, sendo lócus de formação cultural, ela possui limites na capacidade de construir formas inovadoras de incorporação de capitais culturais (BOURDIEU, 2010). Mesmo nos casos em que há sucesso improvável (ZAGO, 2014), percebe-se que ele é alcançado com superações vividas a partir de precários recursos econômicos, sociais e culturais.

Este artigo recorreu à estatística descritiva e buscou articular aspectos do debate acadêmico sobre a complexidade da educação de nível médio para interpretar estratos entre estudantes do último ano em escolas públicas de uma capital brasileira. Por meio da produção de dados quantitativos e qualitativos nas escolas de nível médio, notamos elementos de desigualdades e seletividades nas trajetórias escolares juvenis.

Porto Alegre é uma das maiores regiões metropolitanas do país e possui um Índice de Desenvolvimento Humano (IDH) ${ }^{2}$ relativamente bem posicionado no ranking das capitais brasileiras. Não obstante, encontra muitos problemas na escolarização dos jovens, em parte devido às condições da rede estadual de ensino, com grande alternância de currículos e projetos pedagógicos, além dos baixos salários dos profissionais de educação, falta de concurso público e precária infraestrutura. Para compreender melhor essa situação, revisamos elementos da educação básica nacional e buscamos apresentar dados gerais e específicos que caracterizam o público do ensino médio de Porto Alegre, de modo a visualizar a estratificação e a seletividade escolar.

\section{Universalização do acesso à educação e seletividade no ensino médio}

A Lei 9.394, de Diretrizes e Bases da Educação Nacional (LDB), de 1996, definiu o ensino médio como parte da educação básica, isto é, do nível de ensino de formação comum e obrigatória a todo cidadão brasileiro. Entretanto, no texto da lei, a obrigatoriedade e gratuidade do ensino médio foi inicialmente prevista como progressiva. A Emenda Constitucional no 59 (EC59), de 2009, alterou a situação ao definir a educação básica como obrigatória dos 4 (quatro) aos 17 (dezessete) anos de idade, formalizando o compromisso do Estado brasileiro de universalizar o ensino médio, pelo menos para aqueles na idade esperada.

A definição da obrigatoriedade por faixa etária, entretanto, não corresponde à obrigatoriedade da etapa escolar, particularmente do ensino médio, por ser a última da educação básica. Dada a retenção e a evasão, historicamente, parcela significativa de jovens entre 15 e 17 anos ainda se encontra no ensino fundamental. Quando chegam ao ensino médio (se chegam), já são potenciais estudantes da educação de jovens e adultos (EJA), que ficou preterida pelo texto legal e, consequentemente, pelas políticas públicas. Um indício disso é o complexo processo de juvenilização da

20 Índice de Desenvolvimento Humano (IDH) de algumas regiões metropolitanas do Brasil informa a posição ocupada pela região em questão. Em Florianópolis, o IDH do ano de 2010 era de 0.815 e em 2017, 0,840. Porto Alegre o IDH foi de 0.762 no ano de 2010 e, em 2017, passou para 0,795. Já em Maceió foi de 0.702 e de 0,721, respectivamente nos anos de 2010 e de 2017 (PNUD; IPEA; JFP, 2020 ). 
EJA que vem ocorrendo nas últimas décadas, estimulado entre outros fatores pelo rebaixamento das idades mínimas para exames supletivos, realizado pela LDB de 1996 e, principalmente, pelas políticas de responsabilização das escolas e do corpo docente a partir de avaliações em larga escala (PEREIRA; OLIVEIRA, 2018).

O Plano Nacional de Educação (PNE), Lei 13.005 de 2014, reforçou o compromisso da EC59 ao estabelecer como meta "universalizar, até 2016, o atendimento escolar para toda a população de 15 (quinze) a 17 (dezessete) anos e elevar, até o final do período de vigência deste PNE, a taxa líquida de matrículas no ensino médio para $85 \%$ (oitenta e cinco por cento)" (meta 3). Apesar da formalização legal, 2016 findou sem atingir a meta da universalização e distante da meta de elevação da taxa líquida de matrículas.

De acordo com o Relatório do 2 Ciclo de Monitoramento das Metas do Plano Nacional de Educação, publicado pelo INEP em 2018; em 2017, 91,3\% da população do país com 15 a 17 anos de idade ainda frequentava a escola ou já havia concluído a educação básica. A porcentagem foi calculada pela base de dados do PNAD. No detalhamento por estados, apareciam com as menores porcentagens Alagoas (86,8\%) e Acre (87,1\%). As maiores porcentagens eram de Rio de Janeiro $(94,9 \%)$ e Tocantins $(94,8 \%)$. O Rio Grande do Sul possuía porcentagem próxima, mas abaixo, da nacional, com $90,4 \%$.

Quanto à taxa líquida de matrículas, ou seja, o percentual da população de 15 a 17 anos que frequenta ou concluiu o ensino médio, o mesmo relatório indicou que, em 2017, a taxa nacional era de $70,1 \%$. No detalhamento por estados, lideravam as taxas São Paulo $(82,9 \%)$ e Mato Grosso (79,3\%). As taxas mais baixas eram de Sergipe (54,3\%) e Pará (56,1\%). Dados de 2018, ilustrados no Gráfico 1, evidenciaram que o Rio Grande do Sul conseguiu superar o percentual nacional. Entretanto, a realidade da capital Porto Alegre se mostrou mais desfavorável: cinco pontos percentuais abaixo da do estado e três pontos abaixo da taxa do país. Entre os estudantes matriculados no ensino médio na cidade de Porto Alegre, 27\% possuíam idade superior a 18 anos, um percentual significativamente superior ao do estado e ao do país.

Gráfico 1 - Percentual de matrículas do ensino médio regular, por faixa etária, Brasil, Rio Grande do Sul e Porto Alegre (2018)

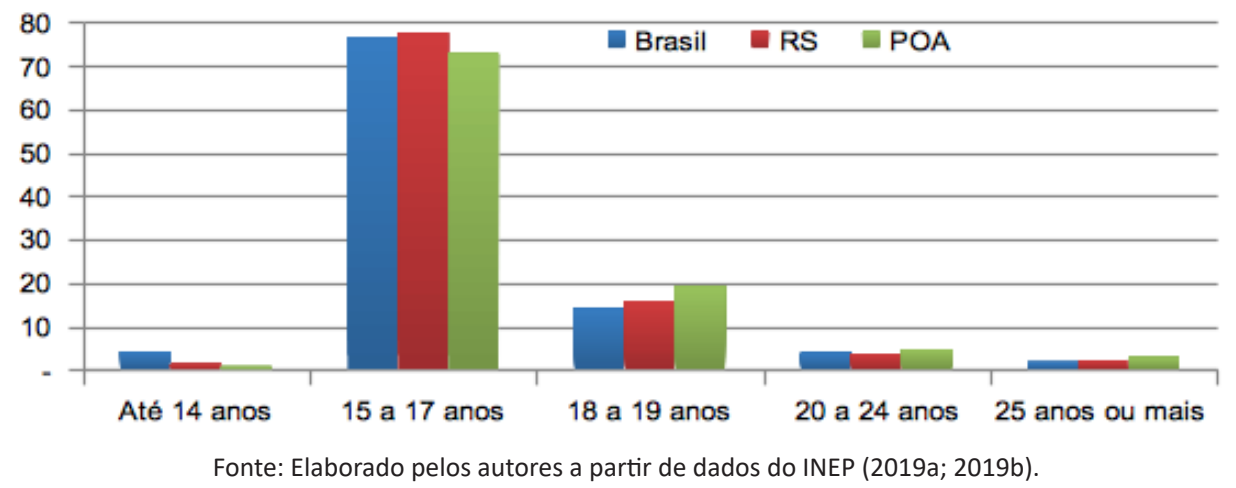

O estado do Rio Grande do Sul e a cidade de Porto Alegre têm seguido a tendência nacional de oscilação nas matrículas no ensino médio. Considerando o período entre 1999 a 2018, notamos (Gráfico 2) que a queda das matrículas em Porto Alegre teve início em 2003, depois de atingir um máximo de 67.740, chegando a um total de $38.312 \mathrm{em} 2018$. Em termos percentuais, em duas décadas, a queda foi de quase $26 \%$. No mesmo gráfico, é possível observar essa tendência de queda das matrículas segundo a rede de ensino e dependência administrativa. Em termos percentuais, a rede privada foi a que teve maior redução, com uma queda de $55 \%$, seguida pela rede pública com $37 \%$. A rede federal teve uma queda de $51 \%$, seguida pela rede estadual, com $37 \%$, e a municipal, com $34 \%$. 
Gráfico 2 - Matrículas no ensino médio regular, Porto Alegre (1999-2018)

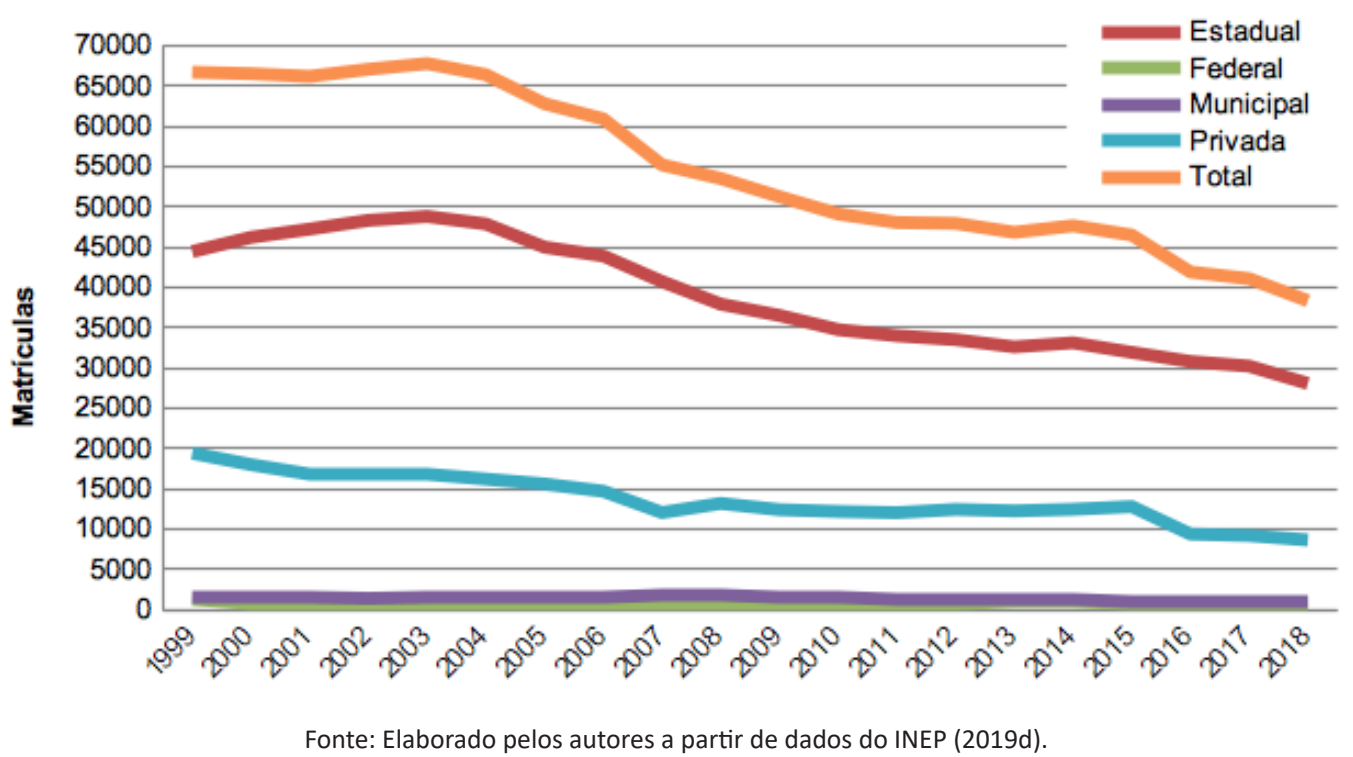

Historicamente, a expansão mais significativa das matrículas no ensino médio no país se deu entre a década de 1990 e o início dos anos 2000, quando o número de matrículas quase triplicou. O ano de 2004 atingiu o maior número já registrado: 9.169.357 matrículas. Entre 2005 e 2007, essas matrículas tiveram expressiva retração. Desde então, há certa oscilação, mas, no geral, o número segue diminuindo.

Um importante fator para compreender tal cenário de retração é o fenômeno da evasão. Em 2017, ele alcançou 6\% das matrículas do ensino médio no país e 7,5\% no estado do Rio Grande do Sul. Na rede estadual de Porto Alegre, chegou a 10\% no primeiro ano do ensino médio; 9,7\% no segundo ano e 6,3\% no terceiro ano. Esse fenômeno ainda carece de estudos qualitativos mais aprofundados, mas com certa frequência é atribuído a questões vinculadas ao mundo do trabalho e à falta de sentido ou de identidade do ensino médio. De qualquer forma, evidencia que a permanência ainda é um importante desafio nessa etapa de ensino.

Cabe destacar também a queda no percentual de estudantes frequentando o terceiro ano do ensino médio em relação ao total de matriculados, que passou de $23 \%$ em 2007 para 19\% em 2018 (Gráfico 3).

Gráfico 3 - Número de matrículas no ensino médio regular segundo o ano, Porto Alegre (2007-2018)

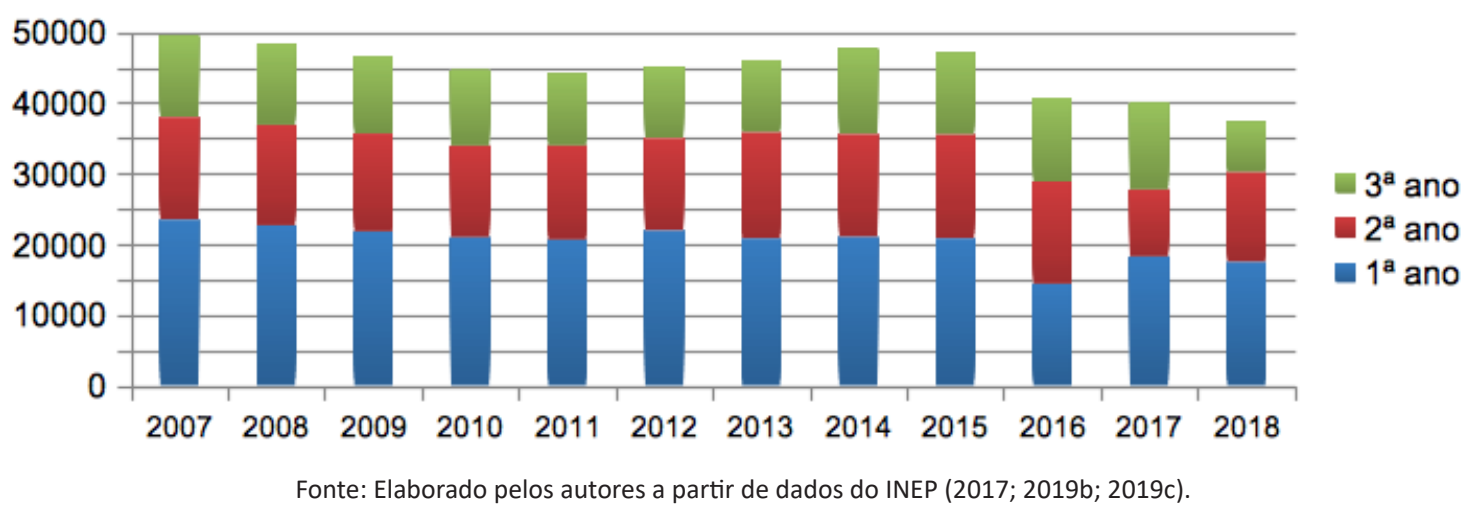

A análise das situações estaduais é importante porque desde a Emenda Constitucional no 14 (EC14), de 1996, formalizou-se a descentralização administrativa do sistema educacional nacional, instituindo a atuação prioritária dos municípios com os ensinos infantil e fundamental e dos estados e do Distrito Federal com o ensino fundamental e ensino médio. No caso do ensino 
fundamental, essa nova configuração contou com repasses do Fundo de Manutenção e Desenvolvimento do Ensino Fundamental e de Valorização do Magistério (FUNDEF). No caso do ensino médio, os estados e o Distrito Federal só passaram a receber fundos específicos a partir de 2007, quando o FUNDEF foi transformado em Fundo de Manutenção e Desenvolvimento da Educação Básica e de Valorização dos Profissionais da Educação (FUNDEB).

É preciso reconhecer que parte significativa das instituições de ensino médio já estava sob a administração dos estados e Distrito Federal muito antes de 1996. O levantamento estatístico de José Marcelino de Rezende Pinto (1996) evidenciou que, em 1992, 68,9\% dos estudantes de segundo grau (atual ensino médio) do país estavam em instituições estaduais. Na região Norte, essa taxa subia para $81,8 \%$ e, na região Nordeste, caía para 58,8\%. Entretanto, com a LDB e com a EC14, formalizou-se sobre eles a responsabilidade de realizar a expansão progressiva do ensino médio, sem fundo específico.

As especificidades desse processo, em sua maioria, ainda precisam ser recontadas e analisadas em suas regionalidades. No entanto, sabemos que, no geral, envolveram superlotação de salas, sucateamento da infraestrutura e desvalorização salarial de profissionais da educação, ao mesmo tempo em que se abriu grande espaço para o setor privado. No Rio Grande do Sul, por exemplo, há problemas de remuneração e de carreira docente, assim como ausência de infraestrutura necessária para o funcionamento das escolas.

Os dados do Censo Escolar dos últimos dez anos, evidenciaram que estados e Distrito Federal mantiveram uma média $83 \%$ a $87 \%$ das matrículas no ensino médio. Houve uma significativa expansão da rede privada, especialmente nos grandes centros urbanos. Em Porto Alegre, por exemplo, o percentual de matrículas na rede privada em 2018 chegou a 22\% do total, enquanto o percentual nacional foi de $12 \%$ e o estadual, 10\%. Não por acaso, no mesmo ano, o percentual de matrículas na rede estadual em Porto Alegre foi cerca de $11 \%$ menor ao total de matrículas em comparação com o país e o estado (Gráfico 4).

Gráfico 4 - Percentual de matrículas do ensino médio regular segundo a dependência administrativa, Brasil, Rio Grande do Sul e Porto Alegre (2018)

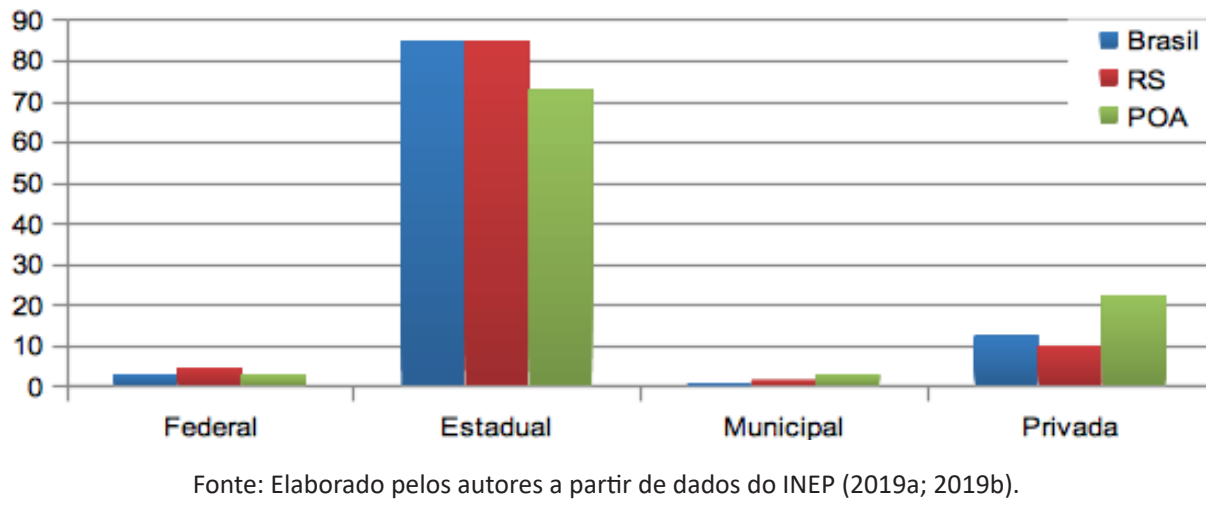

No mesmo período, a rede federal vivenciou significativa expansão relativa, mais que dobrando de tamanho, impulsionada pelos Institutos Federais, com formação de nível médio conjugada à técnica e profissional. A rede municipal, ao contrário, passou por significativa retração, chegando em 2018 a um quarto do que era em 2007.

As iniciativas federais de intervenção sobre essa multifacetada e complexa situação do ensino médio foram majoritariamente curriculares. Em 1998, publicou as Diretrizes Curriculares Nacionais para o Ensino Médio (DCNEM), que foram renovadas em 2012 e atualizadas em 2018. Em 1999, lançou os Parâmetros Curriculares Nacionais para o Ensino Médio (PCNEM), complementados em 2002 pelos chamados PCNEM+. Em 2006, publicou as Orientações Curriculares Nacionais para o Ensino Médio (OCNEM). Mais recentemente, em 2018, aprovou a Base Nacional Curricular 
Comum (BNCC), que estava prevista na LDB de 1996, mas que foi concretizada nos princípios da Reforma do ensino médio apresentada como Medida Provisória no 746/2016 e aprovada na Lei no 13.415/2017, que alterou a LDB principalmente para flexibilização do currículo e da formação docente ao autorizar a contratação de professores por notório saber.

A partir das iniciativas federais, tendo em vista a responsabilidade administrativa, a maioria dos estados do país também fizeram propostas curriculares estaduais, que em grande parte reproduziam em maior ou menor grau o que já estava proposto pelo MEC. Quando analisamos as políticas do estado do Rio Grande do Sul para o ensino médio nesse período, foram propriamente as disputas em torno do currículo que saltaram aos olhos. A exceção talvez seja a elaboração do Plano Estadual de Educação, aprovado em 2014, que, em relação ao ensino médio, repetiu as metas do PNE.

Entre 2007 e 2018, o Rio Grande do Sul viveu três diferentes gestões estaduais, cada uma delas com uma proposta de reestruturação curricular diferente. No governo de 2007 a 2010, de Yeda Crusis (Partido da Social Democracia Brasileira - PSDB), foram entregues às escolas estaduais os cadernos Lições do Rio Grande, que eram uma adaptação estadual aos PCN e ao currículo por competências e habilidades. Na gestão seguinte, de 2011 a 2014, de Tarso Genro (Partido dos Trabalhadores - PT), a comunidade escolar foi envolvida na Conferência Estadual do ensino médio para implementação de uma reforma do ensino médio estadual com três organizações curriculares: Politécnico, curso Normal ou Educação Profissional Integrada, que serviu de vitrine para o Pacto Nacional pelo Fortalecimento do ensino médio lançado pelo governo federal no final de 2013. Por fim, entre 2015 e 2018, o Rio Grande do Sul esteve sob a gestão de José Ivo Sartori (Movimento Democrático Brasileiro - MDB), que também impôs sua orientação curricular para o ensino médio, com uma reestruturação que retomava o princípio curricular de competências e habilidades e inseriu o Ensino Religioso como uma das áreas de conhecimento para o segundo ciclo do ensino fundamental (sexto ao nono ano) e para o primeiro ano do ensino médio. No momento atual, a orientação política educacional para o ensino médio no Rio Grande do Sul é implementar a reforma proposta pela Lei no 13.415/2017 e pela BNCC de 2018, definindo uma nova e drástica mudança curricular.

Tanto em nível nacional quanto estadual, a inconstância curricular evidencia que, apesar do PNE, as ações sobre a educação como política pública ainda são de governo e não de Estado, fragilizando o caráter público da educação escolar. Em decorrência disso, os desafios experimentados pelos jovens na escolarização pública permanecem e se agravam. Mesmo tendo acesso ampliado com a inclusão de novos segmentos estudantis no ensino médio e na continuidade dos estudos, a permanência e o êxito escolar continuam sendo desafio para muitos. Diversos fatores fazem funcionar lógicas de seleção entre aqueles que irão adiante e os que são retidos seja por exames escolares. Esse é o caso dos filhos de trabalhadores pouco escolarizados e portadores de capital cultural pouco afeito a lógica escolar.

\section{Escolarização e seletividade escolar}

Apesar de o processo de escolarização estar vinculado à mobilidade social, ele também é perpassado por seletividades e estratificações. A literatura sociológica mostra que há segmentos da população que, mesmo em condições materiais limitadas, investem na escolarização dos filhos com perspectivas de mobilidade social (BOURDIEU, 2010). No caso brasileiro, as desigualdades sociais e a tardia expansão da escolarização pública complexificaram essas relações.

A trajetória pregressa dos pais e das famílias contribui para a compreensão na medida em que delimita possibilidades futuras. Em muitos casos, os condicionantes materiais e simbólicos impedem ou limitam que indivíduos e segmentos sociais estabeleçam projetos de futuro que levem à superação dos cerceamentos a que estão historicamente submetidos. 
Em período de ampliação do acesso à escola e da obrigatoriedade de estudos, como o que vivemos com o ensino médio no Brasil recentemente, a seletividade e a estratificação evidenciam-se no interior do sistema (BRANDÃO; CARVALHO, 2011), assim como o "efeito escola" (COSTA, 2008). Com mais acesso, há mais inclusão e alguns progressos esperados tornam-se mais difíceis, configurando "excluídos no interior" da dinâmica escolar (BOURDIEU; CHAMPAGNE, 2001).

No contexto da expansão das oportunidades educacionais há disparidades na qualidade da experiência escolar e nas trajetórias dos estudantes, na possibilidade de conclusão do ensino médio ou de ingresso na educação superior. As experiências em um mesmo nível de ensino são díspares de acordo com instituições, currículos, localizações etc. As experiências escolares são distintas entre grupos de jovens e entre os indivíduos. Nesse sentido, François Dubet (2003) explicou que as desigualdades se multiplicam conforme se situam no âmbito da escola, sendo resultados de processos passados e atuais, mas também expondo possibilidades e posições sociais futuras diferenciadas.

A progressão no sistema de ensino tende a aumentar a presença de valores de especialização e de diferenciação (ABRANTES, 2005). Nos anos mais avançados da escolarização, há maiores chances de que as transições entre anos de formação, entre etapas e exames sejam marcadas por situações críticas, habilidades diferenciadas, códigos especializados e, frente a isso, os recursos desiguais entre os indivíduos e segmentos sociais, tende a produzir novos tipos de desigualdades (DUBET, 2003). Assim, a seletividade escolar se apresenta também de forma mais sutil no interior de trajetórias com inserção precárias, vinculando-se aos fenômenos da evasão, da permanência prolongada no sistema e das intermitências.

As desigualdades que ocorrem de diferentes maneiras ao longo da vida escolar são particularmente intensas no ensino médio (CAPRARA, 2013; MENEZES FILHO; KIRSCHBAUM, 2015) mesmo entre aqueles que estão ao final dessa etapa de escolarização. Diante disso, é oportuno investigar quem são os estudantes do terceiro ano do ensino médio de escolas públicas da cidade de Porto Alegre e o que sobressai na caracterização socioeconômica familiar e nos hábitos de estudos deles.

\section{Estratégia da pesquisa}

A estratégia da pesquisa empírica dos dados apresentados na próxima sessão apoiou-se na produção de dados primários por meio de survey realizado junto a estudantes que frequentavam o terceiro ano do ensino médio no ano de 2018. O corpus do survey foi construído a partir da amostra estratificada dos estudantes da rede pública do município de Porto Alegre gerada a partir de dados do censo escolar (INEP, 2018, 2019). Com base no número total de estudantes do ensino médio regular naquele ano (38.312) e com foco nos alunos dos $3^{\circ}$ anos de escolas públicas (6.242), foi calculada uma amostra estratificada (480), atingindo 95\% de confiança e margem de erro de $4 \%$ (Tabela 1). Nos substratos da amostra foram considerados a dependência administrativa das instituições de ensino, o gênero e a etnia dos estudantes. Os dados foram obtidos junto a 14 escolas, com um questionário formado por 46 questões fechadas e duas questões abertas. Buscou-se mapear os diferentes públicos estudantis em sua relação com a educação básica, educação superior e projetos de vida. Nesse artigo, analisamos apenas os aspectos socioeconômicos e culturais desses estudantes, considerando características familiares e escolares. 
Tabela 1 - Composição da amostra estratificada e de questionários aplicados

\begin{tabular}{|c|c|c|c|c|c|c|c|}
\hline & & \multicolumn{2}{|c|}{ População } & \multicolumn{2}{|c|}{ Amostra } & \multicolumn{2}{|c|}{ Survey } \\
\hline & & Total & $\%$ & Total & $\%$ & Total & $\%$ \\
\hline \multirow{4}{*}{$\begin{array}{l}\text { Dependência } \\
\text { Administrativa }\end{array}$} & Estadual & 5949 & 95.3 & 457 & 95.2 & 457 & 95.2 \\
\hline & Federal & 195 & 3.1 & 15 & 3.1 & 15 & 3.1 \\
\hline & Municipal & 98 & 1.6 & 8 & 1.6 & 8 & 1.6 \\
\hline & Total & 6242 & 100 & 480 & 100 & 480 & 100 \\
\hline \multirow{3}{*}{ Gênero } & Feminino & 3237 & 51.9 & 249 & 51.9 & 249 & 51.8 \\
\hline & Masculino & 3005 & 48.1 & 231 & 48.1 & 231 & 48.1 \\
\hline & Total & 6242 & 100 & 480 & 100 & 480 & 100 \\
\hline \multirow{7}{*}{ Etnia } & Brancos & 3209 & 51.4 & 246 & 51.2 & 314 & 65.4 \\
\hline & Pretos & 690 & 11.1 & 53 & 11.0 & 73 & 15.2 \\
\hline & Pardos & 534 & 8.6 & 41 & 8.5 & 76 & 15.8 \\
\hline & Amarelos & 4 & 0.1 & 1 & 0.2 & 6 & 1.3 \\
\hline & Indígenas & 4 & 0.1 & 1 & 0.2 & 6 & 1.3 \\
\hline & Não declarado & 1801 & 28.9 & 138 & 28.7 & 2 & 0.4 \\
\hline & Total & 6242 & 100 & 480 & 100 & 480 & 100 \\
\hline
\end{tabular}

Fonte: Elaborado pelos autores, 2018.

\section{Descrição dos resultados e análise dos dados}

No que tange a aspectos das condições de vida e de escolarização da família, perguntamos sobre a situação de trabalho da mãe ou equivalente responsável (Gráfico 5) e obtivemos que 1,9\% nunca trabalhou, 39,9\% trabalha de carteira assinada, $12,3 \%$ é autônoma sem empregados, 2,7\% é autônoma com empregados, 6,2\% é concursada, funcionária pública, 2,9\% é profissional liberal, $10,2 \%$ realiza atividades domésticas, $10,4 \%$ se encontra desempregada, $5,5 \%$ é pensionista e $7,4 \%$ possui outra atividade profissional.

\section{Gráfico 5 - Situação de trabalho da mãe ou responsável}

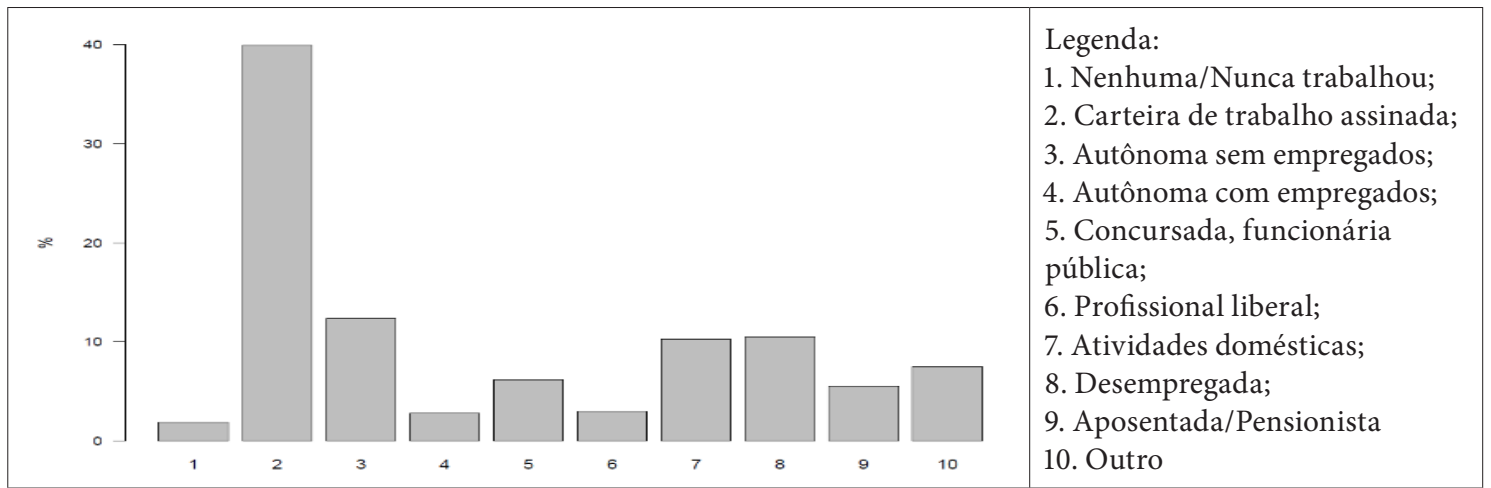

Fonte: Elaborado pelos autores, 2019 
Quanto à situação de trabalho do pai ou equivalente responsável (Gráfico 6), 1,7\% nunca trabalhou, 35,7\% trabalha de carteira assinada, $12,2 \%$ é autônomo sem empregados, $10 \%$ é autônomo com empregados, 9,3\% é concursado, funcionário público, 4,6\% é profissional liberal, 0,6\% realiza atividades domésticas, $5,5 \%$ se encontra desempregado, $7,7 \%$ é pensionista e $12,2 \%$ possui outra atividade profissional.

Gráfico 6 - Situação de trabalho do pai ou responsável

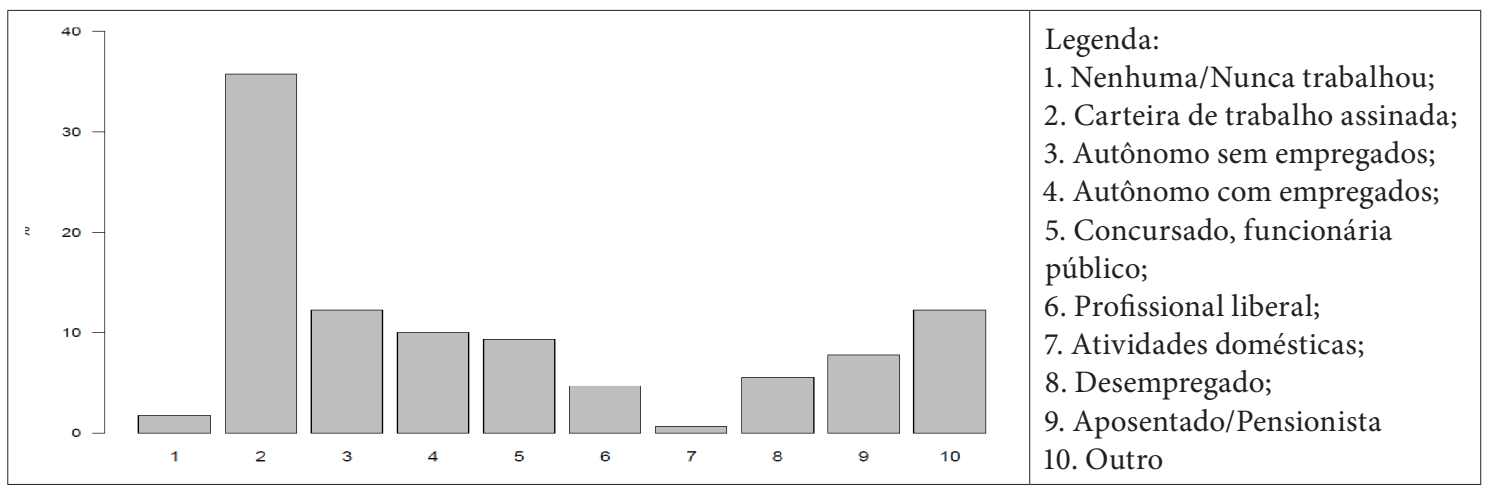

Fonte: Elaborado pelos autores, 2019.

As categorias utilizadas permitem perceber que a maioria de mães, pais ou responsáveis desenvolvia atividades profissionais com carteira de trabalho assinada ou era autônomo sem empregados: $47,9 \%$ dos pais e $52,2 \%$ das mães. As mães, portanto, tem percentual maior nesses tipos de atividades. Elas foram maioria relativa também nos segmentos de atividades domésticas e de desemprego, somando 20,6\%; enquanto os pais somaram $6,1 \%$.

Em relação à própria situação de trabalho dos estudantes, obtivemos que 59,6\% não estavam trabalhando no momento da resposta ao questionário, 8,9\% trabalhavam eventualmente, 16,7\% trabalhavam até 20 horas semanais, $14,8 \%$ trabalhavam entre 21 a 44 horas semanais. Portanto, é possível inferir que, no geral, o segmento de estudantes que está em fase de conclusão do ensino médio público em Porto Alegre possui algum tempo diário ou semanal para dedicação aos estudos. Entretanto, é significativo que 40,4\%, mais de um terço dos estudantes, possuíam algum vínculo de trabalho. Essa situação traduz que uma parcela importante dos estudantes está na condição de que precisa conciliar estudo e trabalho, tendo desde cedo desvantagem em relação àqueles que dispõem de tempo integral para estudos.

No que tange à escolarização, a distribuição dos títulos escolares obtidos pelas mães, pais ou equivalentes responsáveis foi bastante equilibrada, com destaque para certificação escolar do ensino médio. O tratamento dos dados nos informa que $67,8 \%$ das mães e $67,5 \%$ dos pais possuem escolaridade de pelo menos o ensino médio. Em outros termos e confirmando a literatura da Sociologia da Educação, a maioria absoluta dos estudantes de terceiro ano do ensino médio de escolas públicas de Porto Alegre possuem mãe e pai com pelo menos essa mesma etapa da educação básica completa. O que evidencia uma expansão na detenção de títulos escolares médios, ainda que o progresso intergeracional não seja tão amplo.

Com relação à renda familiar mensal, a totalidade das respostas está representada no Gráfico 7. Identificamos que a maioria, 53\%, declarou renda familiar de até três salários mínimos. Esse valor demonstra que os jovens que frequentavam o terceiro ano do ensino médio em escolas públicas de Porto Alegre eram de famílias com renda relativamente baixa. Embora essa situação possa indicar que parte das famílias dos estudantes esteja em situação igual ou pouco acima de grande parte da população brasileira, ela também permite ver que $47 \%$ dos estudantes possui renda familiar de três salários mínimos ou mais. 
Gráfico 7 - Faixas de renda média familiar mensal

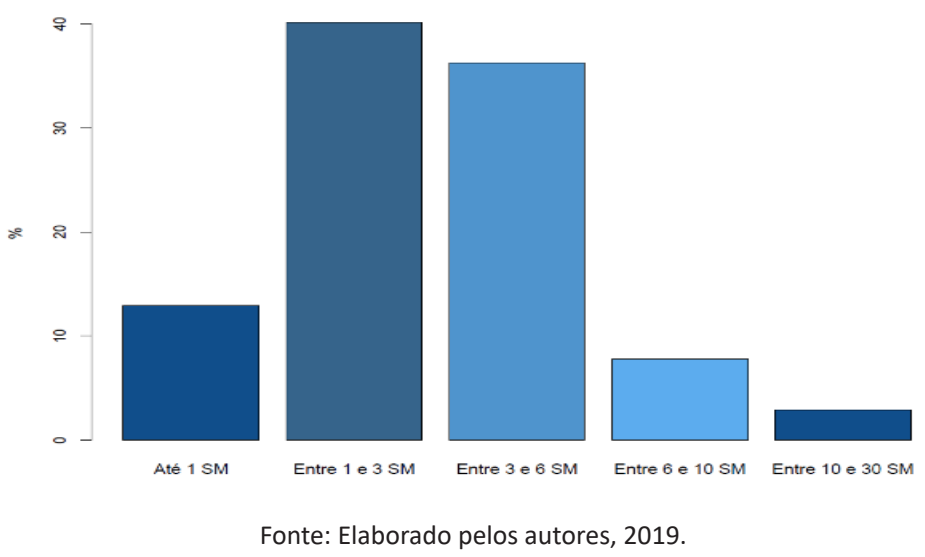

De acordo com dados da Pesquisa Nacional por Amostra de Domicílio do ano de 2018 (IBGE, 2018), 60\% da população brasileira possuía rendimento mensal total entre $\mathrm{R} \$ 153,00 \mathrm{e}$ $\mathrm{R} \$ 1.473,00$. Sabemos que o dado da renda média nacional é limitado, porém serve de parâmetro para perceber que a média do estado do Rio Grande do Sul está acima da do país. Em 2018, a renda média da população brasileira era de $\mathrm{R} \$ 2.234,00$. A do Rio Grande do Sul era ligeiramente maior: R $\$ 2.428,00$ (IBGE, 2018). Nesse sentido, o estado se encontra em posição relativamente menos empobrecida em relação a outros estados brasileiros. Por isso, lidamos com a hipótese de que a grande maioria dos estudantes que frequentam os terceiros anos do ensino médio em escolas públicas da cidade de Porto Alegre pertença a núcleos familiares cuja renda seja maior que a média de rendimentos do estado.

Em relação ao número de quartos nas habitações, a maior parcela, 44,6\%, indicou habitação com dois quartos, seguido por $38,3 \%$ com três quartos. Os estudantes que assinalaram residir em habitações com apenas um quarto foram de 4,5\% e, ainda, 13,2\% responderam residir em habitações com quatro quartos ou mais. Assim, $82,9 \%$ indica viver em habitações de dois ou três quartos, o que sugere uma situação de certo conforto se relacionarmos com o número de moradores indicados na residência que é de até três pessoas em $63,3 \%$ dos respondentes.

O Gráfico 8 representa a totalidade das respostas em relação ao hábito de leitura dos estudantes de terceiro ano do ensino médio das escolas pesquisadas. No total dos estudantes, $28 \%$ não cultivam a prática de ler e $24,5 \%$ leem menos de um livro por semestre. Sabe-se que o hábito da leitura é um elemento formador que oferece recursos - códigos linguísticos, exercícios reflexivos, entre outros - para ampliar o horizonte de possibilidades futuras para os jovens. No entanto, no extremo oposto àquele primeiro segmento de baixos leitores há $2,7 \%$ dos estudantes respondentes que leem mais de seis livros por semestre. A qualidade daquilo que é lido constitui um fator de peso do ponto de vista de acúmulo de capital cultural, porém a simples informação sobre ler livros ou não, com maior ou menor frequência, é significativa porque expõe variação sobre lidar com a língua escrita e seus códigos. Se a média anual de leitura no Brasil é de 2,43 livros por ano, conforme mostra a pesquisa realizada no ano de 2016 (SOMBINI, 2019), 52,5\% dos estudantes pesquisados, estão lendo menos que a média brasileira. É um dado interessante porque também expressa algo sobre nossas escolas e os desafios que enfrentam na formação dos estudantes. Possivelmente estejamos enfrentando limites influenciados pelo fenômeno recorrente descontinuidade curricular, da instabilidade e ausência de aprofundamento relativa a essa prática política educacional. 


\section{Gráfico 8 - Número de livros lidos por semestre}

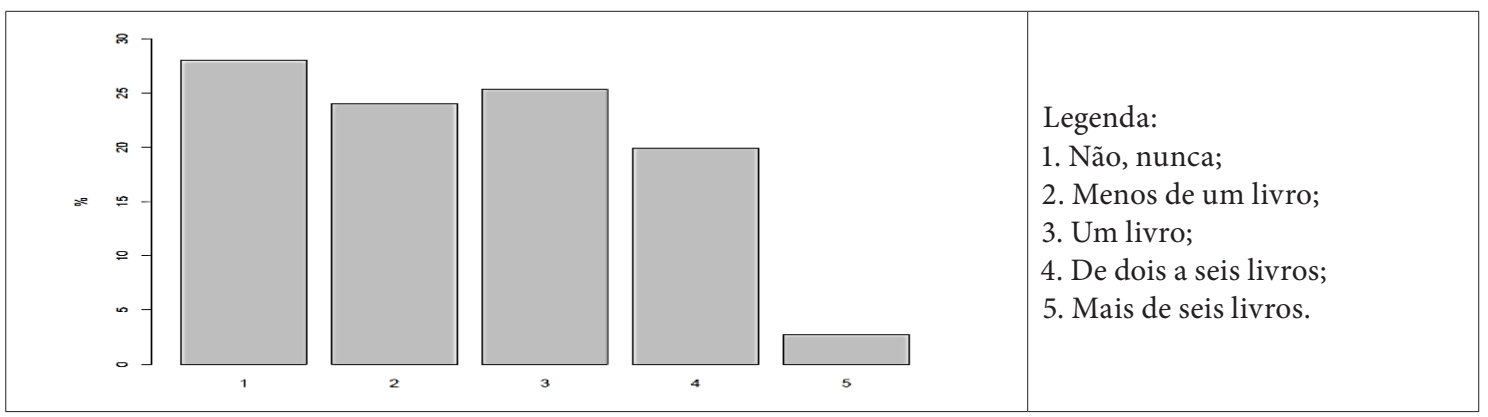

Fonte: Elaborado pelos autores, 2019.

A respeito das horas de estudo semanais fora da sala de aula, os números indicam que $28 \%$ dos alunos apenas frequentam as aulas, não se dedicando aos estudos extraclasse; 57,2\% estudam de uma a três horas para além da escola, 11\% dedicam-se de quatro a sete horas, 2,8\% de oito a doze horas e 1,1\% mais de doze horas de estudos. Assim, 85,1\% informam que não estudam ou estimam dedicar no máximo três horas por semana além das atividades desenvolvidas na escola. Esta questão expõe hábitos de estudos e de relação com tarefas escolares, mas possivelmente indica também o quanto o currículo escolar faz sentido ou não para os estudantes. Nesse caso, lida-se com a possibilidade de que os estudantes consigam aproveitamento no ano escolar sem dedicarem quantidade significativa de horas aos estudos para além da frequência às aulas.

Gráfico 9 - Horas de estudo semanais que o estudante dedica fora da sala de aula

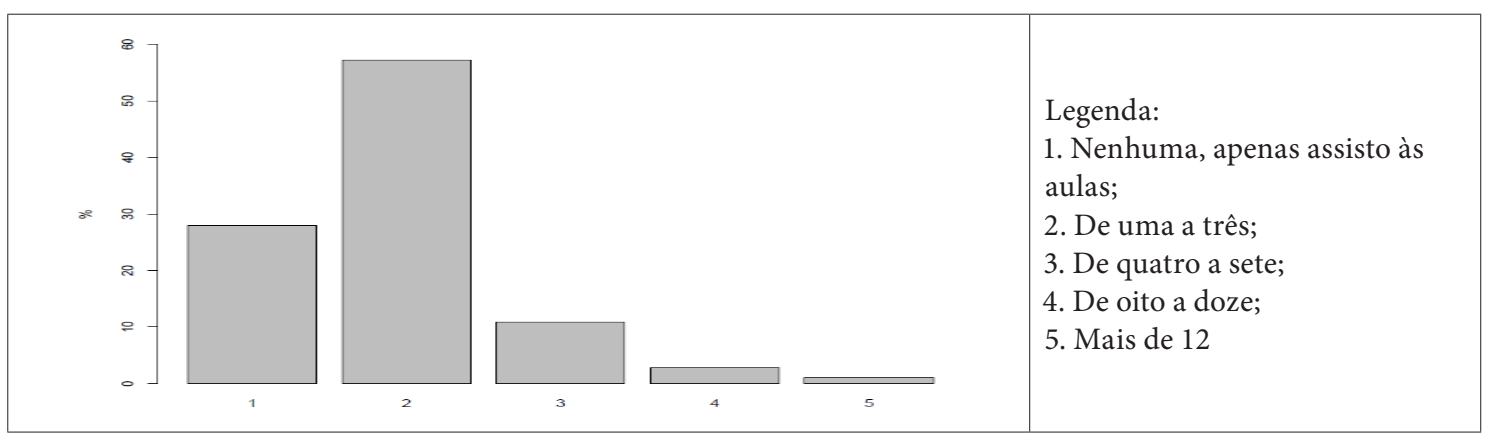

Fonte: Elaborado pelos autores, 2019.

Sobre a consideração do domínio de língua estrangeira, 5,6\% dos participantes responderam que dominam "muito bem" o idioma estrangeiro que conhecem, 20,4\% considerou que dominam "bem", 31\% considerou que "mais ou menos", 22,7\% apontou "pouca" fluência e 20,1\% "muito pouca". Ou seja, 26\% acreditam que dominam bem ou muito bem o idioma estrangeiro. Há aqui um dado importante a ser considerado diante da restrição de oportunidades de trocas no campo cultural e econômico em um mundo globalizado.

Como tendências gerais, a partir do conjunto das respostas apresentadas, identificamos que os estudantes do terceiro ano do ensino médio das escolas públicas de Porto Alegre caracterizam-se predominantemente por pais ou responsáveis com escolarização também de nível médio; renda relativamente mais alta que a média nacional; moradia relativamente cômoda quanto ao número de quartos; poucas horas de estudo para além da frequência à escola; pouco domínio de uma segunda língua.

Essas características nos permitem dizer que entre o público investigado, houve um processo de seleção, já que o ingresso e a formação no ensino fundamental são obrigatórios. Uma vez que o processo escolar seleciona, entre aqueles que avançam nos anos de educação formal, identificamos uma curva de distribuição dos entrevistados de tipo normal, na qual há extremos, os quais 
desenvolvem seus estudos sob condições bastante distintas. Isso pode ser visto entre aqueles que mais estudam e mais leem livros em relação àqueles que só frequentam as aulas, não estudam e não leem. Também pode ser identificado entre pais que não conseguiram obter ou que possuem apenas títulos escolares do ensino fundamental em relação àqueles que obtiveram títulos da educação superior. Pela ótica da escolarização, vislumbra-se que, dependendo das condições conjunturais de desenvolvimento e de oportunidades de trabalho e renda no futuro próximo, há uma tendência a que parte dos estudantes ultrapassem a formação média dos pais, dada pela titulação de nível médio. Ainda que os dados não permitam estabelecer relações diretas entre cada variável isolada e o sucesso escolar, sua leitura conjunta robustece a interpretação de que as condições sociais da família estão fortemente relacionadas às chances de conclusão do ensino médio.

\section{Conclusão}

O conjunto dos elementos apresentados permite entender que os estudantes do último ano do ensino médio público na cidade de Porto Alegre foram selecionados ao longo do sistema de escolarização, em decorrência da ampliação do acesso e da perspectiva de universalização desse nível de ensino. Mostrou-se que há um grupo grande de jovens estudantes no interior de um segmento social que detém certas condições socioeconômicas mínimas e certo capital escolar herdado dos pais. Nesse sentido, pode-se pensar em termos de seletividade escolar que permite a um estrato social progredir na escola e ter a perspectiva de conclusão do ensino médio.

Os dados levantados corroboram com a literatura sociológica (BOURDIEU, 2010; BRANDÃO; LELLIS, 2003; COSTA, 2008; CAPRARA, 2013) que mostra a escola pública com limites importantes na possibilidade de cumprir seu papel social de equalizar oportunidades. Conseguem ter êxito aqueles que cumprem certas pré-condições, em geral, dadas pelos capitais familiares acumulados. De fato, não se ignora o poder de agência dos indivíduos (ZAGO, 2000a, 2000b, 2014) que, sob certas circunstâncias de obtenção de redes de apoio ou de obtenção de pré-requisitos por caminhos diferenciados, conseguem obter êxito e avançar no processo de escolarização, titulação e na mobilidade social que eventualmente essa circunstância proporciona. Isso, entretanto, contribui para evidenciar os processos seletivos e estratificados com base nos quais a escolarização ocorre.

Diante da expansão do acesso ao ensino médio, há que se considerar a existência de grupos ou estratos que se diferenciam das tendências majoritárias. Particularmente, a descontinuidade das políticas estaduais de educação, que se materializa na inconstância de matrizes curriculares, tende a ser um fator negativo para a consolidação e aprofundamento de modos de fazer educação, de promover aprendizagens e de superar limites para o conjunto dos estudantes.

As disputas entre abordagens político-governamentais e a fragilização de políticas de Estado para a educação no Rio Grande do Sul têm deixado de se preocupar com uma questão fundamental para a ótica da Sociologia da Educação. Essa diz respeito à relação entre contexto familiar - capitais acumulados e recursos disponibilizados na trajetória dos estudantes - e desempenho escolar, a fim de remediar injustiças escolares e compensar estratificações internas ao segmento de jovens que frequentam escolas públicas de nível médio.

No que tange à contribuição de estudos acadêmicos para subsidiar políticas públicas para o universo investigado, cabe ampliar o espectro da investigação, reunir elementos mais específicos e qualitativos sobre os modos de organização, hábitos cotidianos e universos culturais de estudantes que se localizem nos extremos da amostra. Tais aspectos auxiliariam a entender como ocorrem as experiências de socialização escolar e como elas dialogam com as necessidades e as aspirações estudantis. Dessa forma nos colocamos o desafio de aprofundar a investigação discutindo, em trabalhos futuros, aspectos sobre o patrimônio disposicional desses estudantes e sobre seus projetos de futuro. 


\section{Referências}

BOURDIEU, Pierre. A escola conservadora: as desigualdades frente à escola e à cultura. In: NOGUEIRA, Maria Alice; CATANI, Afrânio (org.). Escritos de educação. Petrópolis: Vozes, 2010. p. 45-72.

BOURDIEU, Pierre; CHAMPAGNE, Patrick. Os excluídos do interior. In: BOURDIEU, Pierre. A miséria do mundo. 4. ed. Petrópolis: Vozes, 2001. p. 481-586.

BRANDÃO, Zaia; CARVALHO, Cynthia Paes de. Processos de produção das elites escolares. Educação \& Sociedade, Campinas, v. 32, n. 115, p. 507-522, abr./jun. 2011.

BRANDÃO, Zaia; LELLIS, Isabel. Elites acadêmicas e escolarização dos filhos. Educação \& Sociedade, Campinas, v. 24, n. 83, p. 509-526, ago. 2003.

CAPRARA, Bernardo. A influência do capital cultural no desempenho estudantil: reflexões a partir do Saeb 2003. 2013. Dissertação (Mestrado em Sociologia) - IFCH, Universidade Federal do Rio Grande do Sul, Porto Alegre, 2013.

COSTA, Marcio da. Prestígio e hierarquia escolar: estudo de caso sobre diferenças entre escolas em uma rede municipal. Revista Brasileira de Educação, Rio de Janeiro, v. 13, n. 39, p. 455-469, set./dez. 2008.

DUBET, François. Desigualdades multiplicadas. Ijuí: Unijuí, 2003.

FERRETI, Celso João; SILVA, Monica Ribeiro da. Reforma do ensino médio no contexto da medida provisória no 746/2016: estado, currículo e disputas por hegemonia. Educação \& Sociedade, Campinas, v. 38, n. 139, p. 385-404, abr./jun. 2017.

FRIGOTTO, Gaudêncio. A relação da educação profissional e tecnológica com a universalização da educação básica. Educação \& Sociedade, Campinas, v. 28, n. 100, p. 1129-1152, out. 2007.

INSTITUTO BRASILEIRO DE GEOGRAFIA E ESTATÍSTICA (IBGE). Pesquisa Nacional por Amostra de Domicílios Contínua: PNAD Contínua. Rio de Janeiro: IBGE, 2018. Disponível em: https://biblioteca.ibge.gov.br/index.php/ biblioteca-catalogo?view=detalhes\&id=2101673. Acesso em: 10 abr. 2020.

INSTITUTO NACIONAL DE ESTUDOS E PESQUISAS EDUCACIONAIS ANÍSIO TEIXEIRA (INEP). Censo escolar 2016: microdados. Brasília, DF: Inep, 2017.

INSTITUTO NACIONAL DE ESTUDOS E PESQUISAS EDUCACIONAIS ANÍSIO TEIXEIRA (INEP). Sinopse estatística da educação básica 2018. Brasília, DF: Inep, 2019a.

INSTITUTO NACIONAL DE ESTUDOS E PESQUISAS EDUCACIONAIS ANÍSIO TEIXEIRA (INEP). Censo escolar 2018: microdados. Brasília, DF: Inep, 2019b.

INSTITUTO NACIONAL DE ESTUDOS E PESQUISAS EDUCACIONAIS ANÍSIO TEIXEIRA (INEP). InepData. Brasília, DF: Inep, 2019c. Disponível em: http://inep.gov.br/web/guest/inep-data. Acesso em: 15 abr. 2019.

INSTITUTO NACIONAL DE ESTUDOS E PESQUISAS EDUCACIONAIS ANÍSIO TEIXEIRA (INEP). DEED: Diretoria de Estatísticas Educacionais. Consulta matrícula. Brasília, DF: Inep, 2019d. Disponível em: https://inepdata. inep.gov.br/analytics. Acesso em: 15 abr. 2019.

KRAWCZYK, Nora. Reflexão sobre alguns desafios do ensino médio no Brasil hoje. Cadernos de Pesquisa, São Paulo, v. 41, n. 144, p. 752-769, set./dez. 2011.

KRAWCZYK, Nora; SILVA, Cássio José de Oliveira. Desigualdades educacionais no ensino médio brasileiro: uma análise do perfil socioeconômico de jovens que realizaram o Exame Nacional do ensino médio. Sensos-e, Porto, v. 4, n. 1, p. 12-23, 2017.

MENEZES FILHO, Naercio; KIRSCHBAUM, Charles. Educação e desigualdade no Brasil. In: ARRETCHE, Marta (org.). Trajetórias das desigualdades: como o Brasil mudou nos últimos cinquenta anos. São Paulo: Unesp CEM, 2015. p. 109-132.

MOEHLECKE, Sabrina. O ensino médio e as novas diretrizes curriculares nacionais: entre recorrências e novas inquietações. Revista Brasileira de Educação, Rio de Janeiro, v. 17, n. 49, p. 39-58, jan./abr. 2012.

MOLL, Jaqueline. O PNE e a educação integral: desafios da escola de tempo completo e formação integral. Retratos da Escola, Brasília, DF, v. 8, n. 15, p. 369-381, jul./dez. 2014.

PEREIRA, Talita Vidal; OLIVEIRA, Roberta Avoglio Alves. Juvenilização da EJA como efeito colateral das políticas de responsabilização. Estudos em Avaliação Educacional, São Paulo, v. 29, n. 71, p. 528-553, maio/ago. 2018.

PINTO, José Marcelino de Rezende. A divisão de responsabilidades pelo ensino no Brasil e o impacto das mudanças recentes na legislação. Paidéia, Ribeirão Preto, n. 10-11, p. 11-27, ago. 1996. 
PROGRAMA DAS NAÇÕES UNIDAS PARA O DESENVOLVIMENTO (PNUD); INSTITUTO DE PESQUISA ECONÔMICA APLICADA (IPEA); FUNDAÇÃO JOÃO PINHEIRO (FJP). Atlas do Desenvolvimento Humano no Brasil. [S. l.]: PNUD: IPEA: FJP, [2020]. Disponível em: http://www.atlasbrasil.org.br/2013/pt/. Acesso em: 23 abr. 2020.

SALES, Celecina Veras; VASCONCELOS, Maria Aurilene de Deus Moreira. Ensino Médio Integrado e Juventudes: desafios e projetos de futuro. Educação \& Realidade, Porto Alegre, v. 41, n. 1, p. 69-90, jan./mar. 2016.

SOMBINI, Eduardo. Jovens leem mais no Brasil, mas hábito de leitura diminui com a idade. Folha de São Paulo, São Paulo, 28 set. 2019. Disponível em: https://wwwl.folha.uol.com.br/seminariosfolha/2019/09/jovens-leem-mais-no-brasil-mas-habito-de-leitura-diminui-com-a-idade.shtml. Acesso em: 23 abr. 2020.

ZAGO, Nadir. Processos de escolarização nos meios populares: as contradições da obrigatoriedade escolar. In: NOGUEIRA, Maria Alice; ROMANELLI, Geraldo; ZAGO, Nadir (org.). Família e escola: trajetórias de escolarização em camadas médias e populares. Petrópolis: Vozes, 2000a. p. 19-43.

ZAGO, Nadir. Quando os dados contrariam as previsões estatísticas: os casos de êxito escolar nas camadas socialmente desfavorecidas. Paidéia, Ribeirão Preto, v. 10, n. 18, p. 70-80, jan./jul. 2000 b.

ZAGO, Nadir. Um filme pela metade: conteúdos escolares e marcas das desigualdades. Atos de Pesquisa em Educação, Blumenau, v. 9, n. 2, p. 452-471, maio/ago. 2014.

ZIBAS, Dagmar M. L. A Reforma do ensino médio nos anos de 1990: o parto das montanhas e as novas perspectivas. Revista Brasileira de Educação, Rio de Janeiro, n. 28, p. 24-36, jan./abr. 2005.

Data de submissão: 31/01/2021

Data de aceite: 09/02/2021 
Estudantes concluintes do ensino médio público de Porto Alegre...

608 >> Cadernos do Aplicação | Porto Alegre | jan.-jun. 2021 | v. 34 | n. 1 